\title{
Report on ICDP workshop CONOSC (COring the NOrth Sea Cenozoic)
}

\author{
Wim Westerhoff ${ }^{1}$, Timme Donders ${ }^{2}$, and Stefan Luthi ${ }^{3}$ \\ ${ }^{1}$ Geomodelling, Geological Survey of the Netherlands - TNO, Utrecht, the Netherlands \\ ${ }^{2}$ Department of Physical Geography, Faculty of Geosciences, Utrecht University, the Netherlands \\ ${ }^{3}$ Department of Geoscience \& Engineering, Delft University of Technology, the Netherlands
}

Correspondence to: Timme Donders (t.h.donders@uu.nl)

Received: 18 February 2016 - Revised: 20 April 2016 - Accepted: 9 June 2016 - Published: 10 August 2016

\begin{abstract}
ICDP workshop COring the NOrth Sea Cenozoic focused on the scientific objectives and the technical aspects of drilling and sampling. Some 55 participants attended the meeting, ranging from climate scientists, drilling engineers, and geophysicists to stratigraphers and public outreach experts. Discussion on the proposed research sharpened the main research lines and led to working groups and the necessary technical details to compile a full proposal that was submitted in January 2016.
\end{abstract}

\section{CONOSC project aims}

The COring the NOrth Sea Cenozoic (CONOSC) project aims for continuous coring of the Cenozoic sedimentary record of the southern North Sea Basin. The headlines of the planned research are summarized in two main questions.

- What is the long-term interaction between sediment accumulation and climate change?

- How does geographical isolation impact ecosystems divergence?

In order to achieve this one has to investigate source-sink interrelationships, carbon burial, and river development in relation to changing Cenozoic climate gradients and evolving alpine tectonics in a site where terrestrial and marine signals can be integrated and compared. Furthermore, a highresolution geologically and climatologically based timescale calibration of north-western Europe is needed to analyse the Cenozoic extinction rates, speciation, and migration patterns. The southern North Sea Basin combines a continued setting at the hinge line of land and sea, and active subsidence through much of the Cenozoic to meet conditions for obtaining such an integrated record.

Secondary objectives of the drilling project include detailed and direct downhole geophysical monitoring of natural and human-induced seismicity.
Although the North Sea Basin (NSB) is extensively drilled for hydrocarbons, the Cenozoic part of the infill is generally not targeted and high-quality cores as well as a highresolution stratigraphical framework for this era are lacking. Therefore, CONOSC aims to drill the Cenozoic sedimentary record at two onshore sites in the Netherlands that collectively span the larger part of the Cenozoic in a marginal marine geological setting. The Quaternary and Neogene record will be targeted in the Roer Valley Graben in the south of the country, while the Paleogene will be retrieved from welldeveloped sequences in the northern part of the Netherlands. It is intended to core the full Cenozoic sequence at both sites, respectively ca. 1800 and ca. $1000 \mathrm{~m}$.

The ICDP workshop in Driebergen/Utrecht addressed four main topics. First and foremost the science questions and technical challenges, such as downhole seismic monitoring. What is the problem to be solved and how innovative are the scientific contributions? Secondly, the feasibility of the project: what is known about the drilling sites, technical operations, well-logging methods, core treatments, and sampling? Furthermore, attention was paid to scientific partnerships and cooperation with external partners like E\&P operators, regional authorities, and partners active in geothermal energy and subsurface storage. Finally, ideas on outreach and education were discussed. 


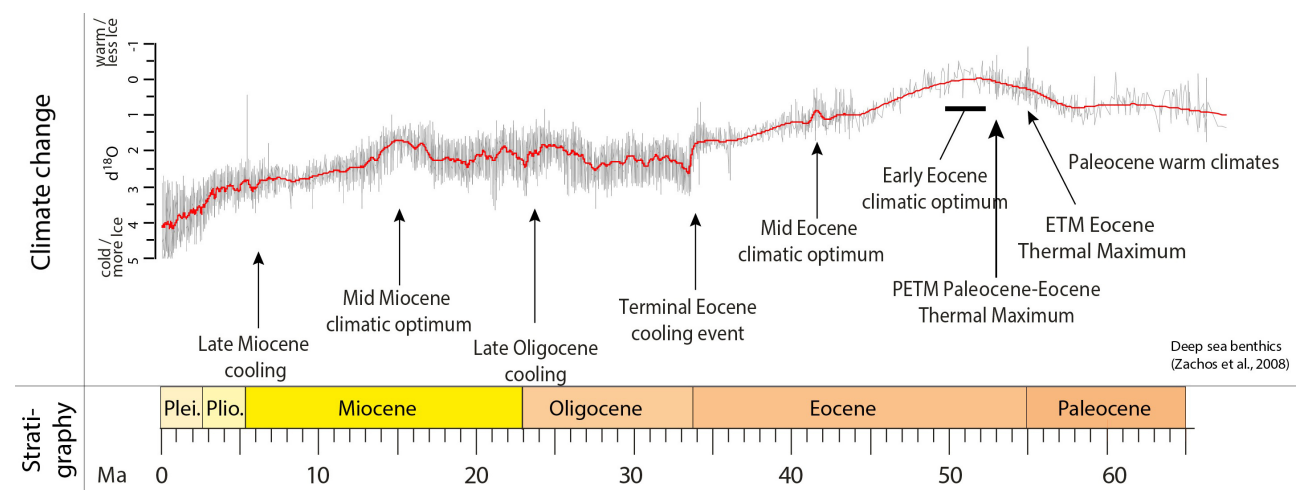

Figure 1. The main Cenozoic global climate events along the deep sea benthic isotope record (Zachos et al., 2008).

The CONOSC research plan is subdivided into six main themes, of which the discussion highlights are summarized in the following.

\section{Palaeoclimatology and palaeobiology}

One of the important issues in palaeoclimate and palaeobiology is that a high-resolution record of the Cenozoic in the NSB can be tied firmly into a regional and global context, and patterns can be quantified and compared. The cored Cenozoic sequences will provide detailed analysis of a number of globally significant events ranging from the early Eocene thermal maxima (PETM, ETM2, Fig. 1) to the conditions surrounding the arrival of hominins in north-western Europe and their impact on the NSB (Fig. 2). A key aspect is that the Cenozoic cooling seems much stronger here than in other parts of the world at similar latitudes, and that especially seasonality of the climate increased. Throughout the Cenozoic, the target regions experienced climates ranging from subtropical swamps to polar desert. Hence, the retrieved record can help to improve modelling warm temperatures at high latitudes (polar amplification), and specifically detect the varying role of the North Atlantic current in this region.

Both marine and terrestrial ecosystems experienced dramatic turnovers throughout the Cenozoic, but only partly due to climate. In north-western Europe in particular, increasing isolation though orogeny and seaway closure dramatically reduced the flora and faunal exchange and migration, leading to extinction and endemism. This may include the floristic response to increasing geographical (Alpine, Carpathian) isolation of northern Europe. But it will also show the effects on biogeography and evolution resulting from the closure of the Oligocene-Miocene interior seaways between the North Sea and the Mediterranean and the Paratethyan system. The rates and response times of these ecosystems transitions are key data that are currently lacking.

As the targeted sediments were deposited in a marginal shallow marine setting, they can contribute to understanding climate-induced changes of the terrestrial ecosystem with changing marine facies systems. Combined with a number of other proxies the pattern of changing (palaeo)climate can make a significant contribution to the understanding of the Cenozoic evolution of the NSB system. It also may contribute to understanding migration pathways of exotic species, especially during the lower Cenozoic in the NSB.

Other issues in this theme concern hydrological changes and sediment transport through river input during hyperthermals and subsequent cooling stages, to indicate signals for volcanism and tectonics, and the extent of euxinia in the NSB.

It is considered vital that a great number of biological and chemical proxies be analysed. Organic fossil groups are known to be very important in the basin (pollen and spores, dinoflagellate cysts), but also benthic and planktic foraminifera, and in selected intervals also nannofossils and molluscs. A number of geochemical techniques may be applied, e.g. stable isotopes, Rock Eval pyrolysis for the hydrogen and oxygen index ( $\mathrm{HI}$ is a measure of the hydrogen richness in marine algae, lipids and proteins; OI measures the oxygen richness of a source rock due to high $\mathrm{CO}_{2}$ and land plants, e.g. cellulose), which can be used in conjunction to estimate the origin of organic matter and thermal maturity of source rocks, $\mathrm{TEX}_{86}$, and related lipid biomarker-based paleothermometers, combined with compound-specific $\delta^{13} \mathrm{C}$, will be key to obtaining absolute climate reconstructions. Furthermore, it was suggested to incorporate outcrop studies available from the marginal areas of the NSB.

\section{Stratigraphy and geochronology}

A well-dated and detailed stratigraphical record of the marginal sedimentary record in the southern NSB is a prerequisite for establishing the palaeoclimate and palaeovegetational response from greenhouse to icehouse on the margins of this mid-latitude marine basin. Established timescales do provide a rough calibration, but the increasing isolation and changing biogeography and sediment provenance mean that many timescales are "floating" chronologies in north-western 


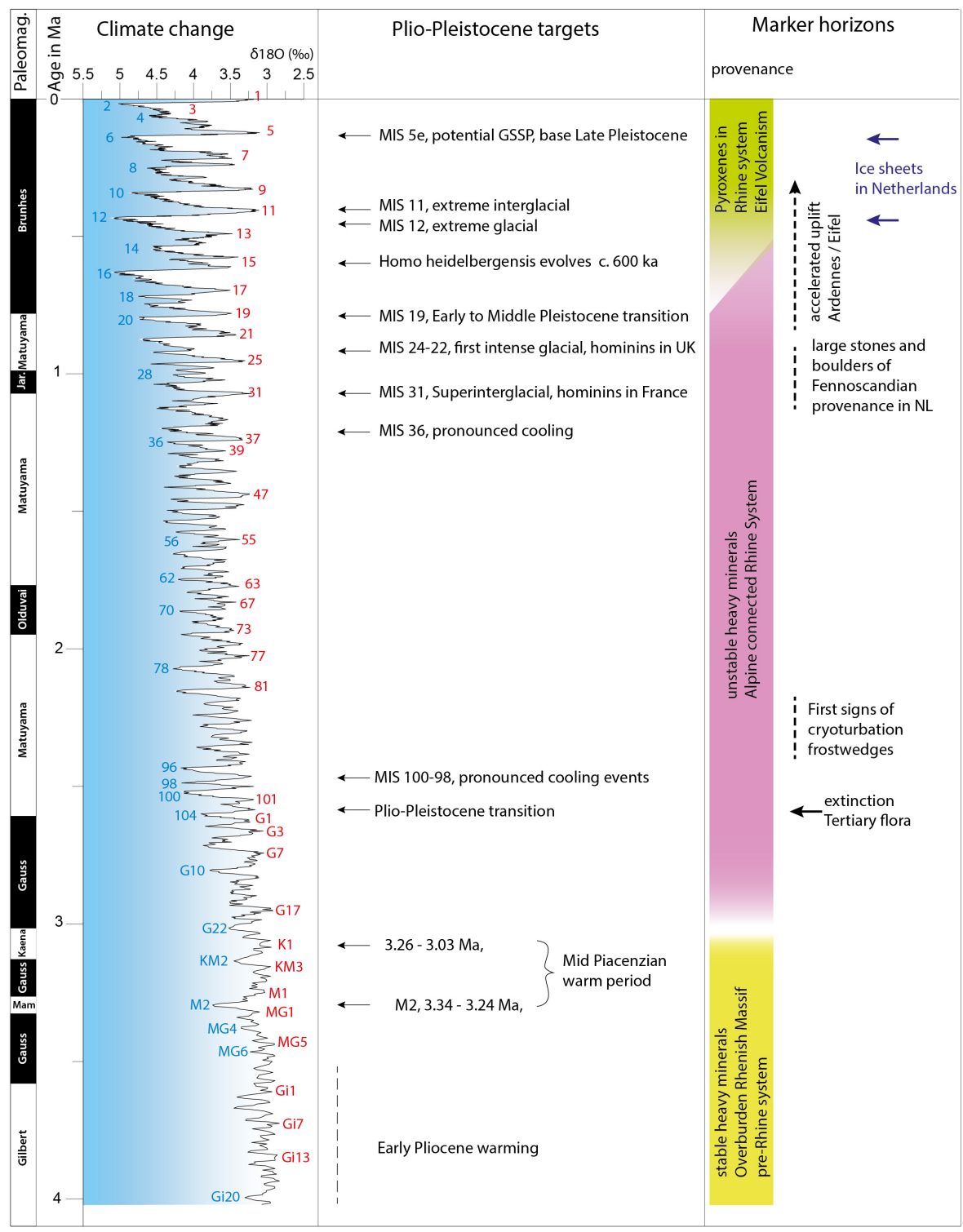

Figure 2. Late Pliocene-Pleistocene targets against the deep see benthic oxygen isotope stack of Lisiecki and Raymo (2005). The climate/vegetational context is very important for landscape reconstruction with respect to the northward migration of hominins.

Europe. Existing but outdated terrestrial standards can be much improved by providing the regional catchment-scale signals integrated with marine proxies. The improved biostratigraphy will allow a significant amount of earlier biostratigraphical work to be reappraised and integrated into a new synthesis for the regional Cenozoic basin evolution.

There are good opportunities to provide an integrated stratigraphy with dinoflagellate cysts as backbone, complemented with calcareous microfossils, potentially nannofossils, magnetostratigraphy, and selected calibration points from geochronology (e.g. OSL, ${ }^{40} \mathrm{Ar} /{ }^{39} \mathrm{Ar}, \mathrm{U} / \mathrm{Pb}$, $\left.{ }^{130} \mathrm{Th} / \mathrm{U}\right)$. The integration of various approaches allows new dating methods to be tested (feldspar and quartz OSL). The development of a NSB cyclostratigraphy will be enhanced by downhole logging and imaging, high-resolution XRF core scanning, and analyses of other proxies (i.e. organic geochemistry, stable isotopes, magnetic susceptibility, tephra, and microtektites). Finally, a firm geochronology will give insights into the long-term climate-related changes in sediment supply.

\section{Geohazards and monitoring}

Current induced seismicity in the northern Netherlands urgently requires improved monitoring and fundamental knowledge of the exact origin to improve risk assessments 


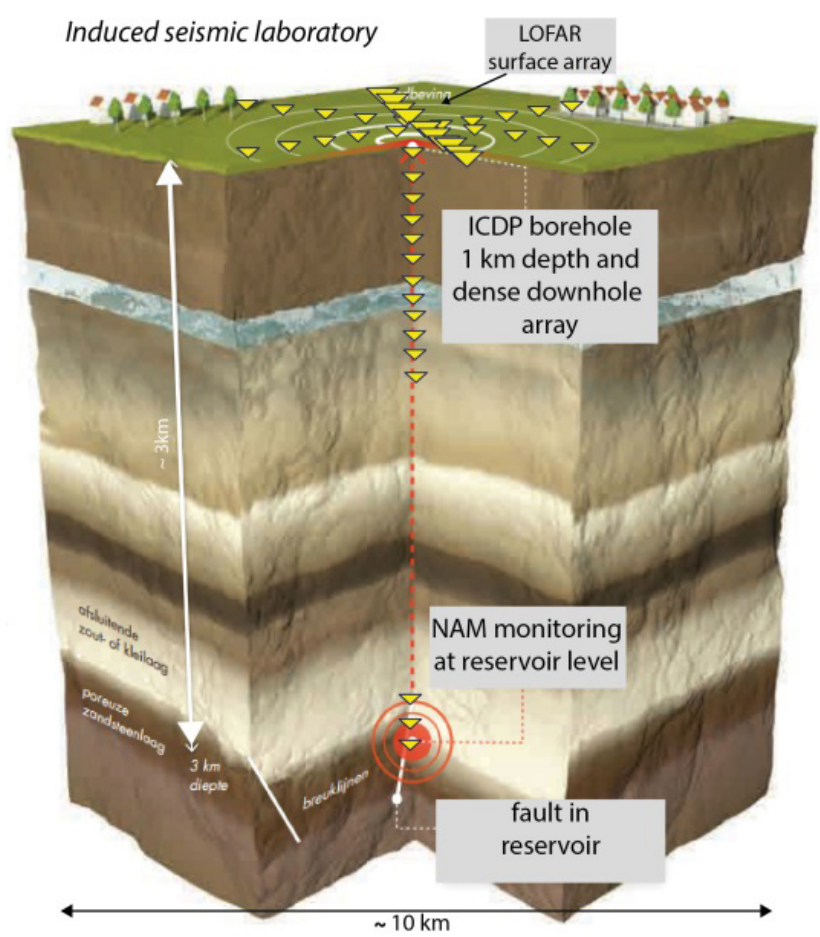

Figure 3. Schematic representation of a dense downhole array of seismic sensors coupled with a LOFAR surface array. Potential monitoring at the reservoir level falls outside the scope of CONOSC.

of mature gas fields in inhabited areas. The scientific drilling provides the opportunity to implement long-term seismic monitoring (more than 10 years) after coring, and possibilities for additional monitoring are being investigated (e.g. downhole temperatures, dynamics of freshwater to saltgroundwater transition, downhole pressures, and Earth magnetism). The seismic monitoring will be incorporated into the existing KNMI/NAM and LOFAR (low-frequency array) seismic 2-D networks (Fig. 3). The great depth (up to $1000 \mathrm{~m}$ ) of installed sensors and the coupling to the LOFAR network will provide a 3-D component to the existing surface-based sensor networks. Due to the increasing number of human-induced earthquakes (resulting from gas extraction), there is high societal relevance for monitoring the northern site. The southern site is situated in the Roer Valley rift systems where naturally occurring earthquakes have been recorded since the Middle Ages. The largest known earthquake there had a magnitude of $M=5.8$ in 1992 in the town of Roermond.

Scientifically long-term seismic monitoring is necessary for an in-depth understanding of induced earthquakes, fault reactivation, and rupturing. Data retrieved from greater depths are needed for validating existing geomechanical models. The dense downhole array will provide data that can be used to fill in the existing gap in regional-scale earthquake monitoring $(M \geq 1)$ and reservoir-scale smaller seismicities
$(M \sim-2 /-3)$. Furthermore, it is expected that earthquake detection and localization, especially below $M \sim-1$, will be improved considerably. Cooperation with NAM, operator of the large Groningen gas field, at the northern site may lead to a worldwide unique monitoring site in a producing gas field.

\section{Physical properties and well logging}

The scientific questions comprise such issues as sedimentation rates and cyclicities, which is a subject that is strongly related to a continuous and accurate geochronology. Palaeomagnetic logging is seen as a prerequisite for retrieving a highly accurate age model of the cored sequences. Careful core scanning can help to detect volcanic ash layers and even impact ejecta which may be very useful time markers. Core scanning and analysing provide detailed insights into a number of layer properties so far unknown for the Cenozoic sediments in the NSB. This includes amongst others the fundamental properties of clays (e.g. the Boom clay), quantification of heterogeneities and hydromechanical properties, etc. Gas (hydrocarbons and $\mathrm{CO}_{2}$ ) in Cenozoic sediments forms an additional issue. Do we understand origin, timing, volumes, and gas-seepage systems that also have palaeoclimatic significance? In some cases high-quality, pressurized sampling is needed. The analysis of pore fluids also demands innovative approaches and careful sample treatment.

Combining geophysical subsurface monitoring methodologies and the downhole variations in properties is needed to improve the interpretative value of these methods. Timelapse gravimetry can be applied to improve shear-wave and induced earthquake models.

\section{Sedimentology and provenance}

To determine the source and volumes of sediments deposited in the NSB, provenance studies have to be carried out. This can be done by combining different provenance indicators (e.g. XRF - bulk geochemistry; isotope analysis on zircons, micas, and feldspars; analyses of grain size and shape; pollen as source markers; clay mineralogy; and analysis of apatite fission-track provenance ages). A full data integration of these different proxies is seen as an innovative challenge: how to discriminate significant signals from general noise in the data sets and how to combine the provenance proxies with marine palaeobiological proxies? Complicating factors will be the reworking of sediment and lost or buried source areas. It is of great importance that existing archives of data (e.g. heavy mineral data at geological surveys and universities) can be explored and combined with newly retrieved data from the cores. Provenance data and a reliable age model will improve the insights into the evolution of drainage networks supplying sediment to the NSB. With respect to this aspect, the project will generate new palaeogeographical maps, and 
thus the (neo)tectonic and morphological evolution of the NSB will be known in greater detail than before.

\section{Societal relevance and cooperation}

Deep drilling up to $1000 \mathrm{~m}$ or more is often related to practical issues like mining, exploration, and exploitation of energy, water resources, and a number of governmental objectives. However, ICDP projects are primarily conducted to elucidate fundamental scientific questions and innovations.

Therefore, cooperation with industrial and scientific partners is of vital importance. In the course of developing a full proposal the CONOSC project has already involved a number of third parties that are interested in cooperating and contributing to the project. Some of them made specific demands on sampling; others will provide "in kind" contributions. It is intended to incorporate these activities as much as possible in the full proposal.

Equally important is the outreach to the general public and to explain why the scientific community conducts such a deep coring project in the NSB. Why do we want to know in great detail the past climate and evolution of the NSB, and why is Earth science a relevant science?

As the Netherlands is a densely populated country, public support and therefore outreach are of utmost importance. The CONOSC project has to generate early and open information channels to the broader public. Interest in CONOSC should be generated by linking the project to issues that are in the minds of people. Professional documentaries and videos showing the development of the project and the execution of the coring and sampling are seen as ways to help the project be embraced by the public. Recent IODP (https://www.iodp.org/multimedia) and ICDP expeditions (http://www.icdp-online.org/media/video-archive) have over the past years increased their outreach and education activities. Some recent videos were shared at the workshop, and it was decided that multimedia productions will be a key aspect of the communication surrounding CONOSC.

\section{Final remarks}

Numerous additional issues were discussed during the workshop that cannot be covered in this brief report. However, all information will used to compile the full proposal. Practical but crucial issues on sampling and coring will be elaborated in the next months. In order to get a quick initial idea on the ages and ranges of the cored sections, it is agreed that first a biostratigraphical analysis will be carried out on core catcher material. All discipline groups will use standardized analytical methods and we will also work on a generally applicable system for data management and evaluation. It is intended that the Geological Survey of the Netherlands will take care of core storage and sample treatment (i.e. core scanning, description, photographs, sub-sampling session). Together with
ICDP they will look for the best solution in data management tools.

All participants, including potential partners to cooperate with, are thanked for their valuable contributions to the workshop and their open-minded attitude during the various discussions.

More information on CONOSC and its progress can be found on the project's websites (http://conosc.geo.uu.nl/; http://www.icdp-online.org/projects/world/europe/ north-sea/).

Those interested in joining the CONOSC challenge are invited to contact Timme Donders (t.h.donders@uu.nl).

Acknowledgements. The authors wish to thank Paul Pearson and Phil Gibbard for their constructive reviews. ICDP is gratefully acknowledged for providing workshop funding.

Edited by: T. Wiersberg

Reviewed by: P. Gibbard and P. Pearson

\section{References}

Lisiecki, L. E. and Raymo, M. E.: A Pliocene-Pleistocene stack of 57 globally distributed benthic D18O records, Paleoceanography, 20, PA1003, doi:10.1029/2004PA001071, 2005.

Zachos, J. C., Dickens, G. R., and Zeebe, R. E.: An early Cenozoic perspective on greenhouse warming and carbon-cycle dynamics, Nature, 451, 279-283, doi:10.1038/nature06588, 2008. 